\title{
Multi-insecticide susceptibility evaluation of dengue vectors Stegomyia albopicta and St. aegypti in Assam, India
}

\author{
Kavita Yadav ${ }^{*}$ Bipul Rabha, Sunil Dhiman and Vijay Veer
}

\begin{abstract}
Background: Dengue is rapidly expanding mosquito-borne viral infection globally facing operational challenges due to insecticide resistance in dengue vectors. We have studied the susceptibility status of potential dengue vectors St. albopicta and St. aegypti to the commonly used insecticides.

Methods: Stegomyia larval bioassays were carried out to determine $L_{10}, L_{50}$ and $L C_{99}$ values and resistance ratios $\left(\mathrm{RR}_{50}\right.$ and $\left.\mathrm{RR}_{99}\right)$ for temephos. Adult susceptibility bioassay to 4\% DDT, 0.05\% deltamethrin, 5\% malathion was assessed following standard procedure to determine the corrected mortality. Knock-down times (KDT 50 and KDT ${ }_{99}$ ) were estimated and the knock-down resistance ratios (KRR ${ }_{50}$ and $\left.K R R_{99}\right)$ were calculated.

Results: St. albopicta wild population (WP) of Sotia was resistant to temephos as the $L C_{99}$ value was $0.12 \mathrm{mg} / \mathrm{l}$ and found to be 2.3 fold high than the reference population (RP). St. aegypti WP of Borgong, Kusumtola and Serajuli displayed a RR ${ }_{99}$ of 2.5, 5.4 and 4.5 respectively suggesting high level of resistance to temephos. Results suggested that both St. albopicta and St. aegypti WP were fully resistant to DDT (mortality $<90 \%$ ) in all the study locations. Both the species were completely susceptible to deltamethrin and malathion (corrected mortality > 98\%), except for St. albopicta at Sotia which displayed low level of resistance to malathion (corrected mortality $=95.4 \%$ ). The estimated KDT values for both the species indicated high level of knock-down resistance to DDT and susceptibility to deltamethrin.

Conclusion: WP of both the dengue vectors showed varied response to temephos, while resistant to DDT and completely susceptible to deltamethrin. Both the species were susceptible to malathion at majority of the testing sites. Current results strongly advocate that DDT is no longer effective against dengue vectors, while thorough monitoring of malathion susceptibility in geographical area at dengue risk is inexorable to ascertain whether or not the resistance to malathion is focal. Information generated herein may be useful in better planning and implementing in dengue control strategy using insecticides.
\end{abstract}

Keywords: St. albopicta, St. aegypti, Dengue vector, Northeast India, Insecticide resistance

\section{Background}

Dengue is the most important and rapidly expanding mosquito-borne viral infection, which is often inapparent but may develop into potentially lethal complications. The World Health Organisation (WHO) has estimated over 30-fold increase in global dengue incidences during the past 5 decades. About 50-100 million dengue cases are reported annually and almost half the world's population is at risk of dengue infection [1].

\footnotetext{
* Correspondence: kavitanami@gmail.com

Defence Research Laboratory, Tezpur, Assam 784 001, India
}

Although dengue fever is a global concern now, at least $75 \%$ of the population exposed to dengue lives in the Asia-Pacific region. In India, dengue is spreading into the new areas and emerged as a major public health problem in the recent years. The effort to restrain dengue transmission primarily focuses on the vector control using insecticides and reducing mosquito breeding sites. However, the control efforts targeting efficient vectors St. albopicta and St. aegypti have failed to curb the increasing incidence of dengue epidemics and its invasion into the new geographical areas [2-4]. 
Dengue interventions using insecticides mainly target the immature stages of mosquitoes which breed in the artificial containers near the human houses and adult stages which actually transmit the dengue virus. The organophosphate (OP) compound temephos has been used to control the immature stage of dengue vectors for some time now $[5,6]$ and probably resulted in the development of temephos resistance in many American [6] and Asian countries [7-9]. In India, although the dengue vector has been reported to be sensitive to temephos in many places $[10,11]$, but as a consequence of widespread use the extent of temephos resistance may have been underestimated due to the lack of comprehensive data from different regions.

DDT, deltamethrin and malathion are commonly used insecticides to control the adult mosquito vectors, however resistance to these insecticides has been reported in many mosquito vectors in different countries [8,9,12-16]. Recent studies from endemic areas of India have reported the DDT resistance in dengue and other mosquito vectors, however there was decreased susceptibility to malathion, permethrin, deltamethrin, lambda-cyhalothrin and cyfluthrin in the majority of the tested mosquito vectors [11,14-16]. Not much data at regional level is available on the resistance status of dengue vectors in India, therefore evaluation of the efficacy of commonly used insecticides in different settings is inevitable under present circumstances.

The study area is endemic to malaria, however in recent years dengue cases have increased significantly [4,17]. Therefore the present study was conducted to determine the resistance level of field collected dengue vectors St. albopicta and St. aegypti in Sonitpur district of Assam to generate practical information which may be useful for taking up more effective vector control measures in future.

\section{Methods}

\section{Stegomyia mosquito collections}

St. albopicta and St. aegypti mosquitoes (immature stages; $F_{0-}$ generation) were sampled from nine localities in Sonitpur district of Assam, India (Figure 1) during March-October 2013. For each collection site, mosquitoes were collected from 6-8 breeding places in domestic, peri-domestic and natural environments. Mosquitoes were stored in plastic tubes containing water from the same breeding habitat and transferred to the laboratory. In laboratory, the WP of Stegomyia mosquitoes collected from different locations were reared separately to the adults and the F1-generation was used for larval and adult bioassays. Additionally, a St. aegypti population was also collected from Nameri National Park (GPS location: $27.0100^{\circ} \mathrm{N}, 92.7900^{\circ} \mathrm{E}$ ), which is sylvan and hence considered as a susceptible reference population (RP) for wild collected St. aegypti populations (WP). St. albopicta mosquitoes are regularly maintained at the insectary of Defence Research Laboratory, Tezpur at controlled conditions $\left(28^{\circ} \mathrm{C} \pm 2^{\circ} \mathrm{C} ; 80 \% \pm 10 \% \mathrm{RH}\right)$ and were taken as RP for the St. albopicta WP mosquitoes.

\section{Larval susceptibility tests}

Larval sensitivity to temephos (90.7\% pure; Heranba Industries Ltd., Mumbai) was determined using standard WHO bioassay [18]. Temephos stock solution of $1 \mathrm{ppm}$ and subsequent dilutions were prepared in 95\% ethanol and stored at $+4^{\circ} \mathrm{C}$ for use in the susceptibility tests. Susceptibility tests were conducted using 15-25 third instar larvaes (both WP and RP) in plastic disposable cups filled with required concentration of insecticide solution and millipore water (Milli-Q, MA, USA) at room temperature $\left(28^{\circ} \mathrm{C} \pm 2^{\circ} \mathrm{C}\right)$. Four different concentrations $(0.001,0.005,0.01$ and $0.05 \mathrm{ppm})$ were evaluated and each test was repeated at least three times [16]. The tests were accompanied by control tests to which only $95 \%$ ethanol in equal concentration was added into the water. Mortality was calculated after 24 hours of exposure.

\section{Adult insecticide susceptibility tests}

Adult insecticide susceptibility bioassays were carried out using WHO test kits [19]. The insecticides impregnated papers used were obtained from Vector Control Research Unit (VCRU), Universiti Sains Malaysia, Malaysia. Bioassays were conducted using 4\% DDT, $0.05 \%$ deltamethrin and $5 \%$ malathion. For DDT, the diagnostic concentration as per WHO criteria was used whereas for deltamethrin and malathion, the diagnostic concentrations from previous studies were used $[11,16,20,21]$. Unfed females (3-5 days old) were exposed to the insecticide impregnated papers in the batches of 10-15 for 60 minutes and cumulative knock-down was recorded after every 5 minutes. After 60 minutes, the survived mosquitoes were transferred to $\mathrm{WHO}$ holding tubes and fed on $5 \%$ sucrose solution for the next 24 hours. Mortality was recorded after 24 hours and graded for sensitivity status [22]. The control tests were performed using silicone oil, olive oil and risella oil pre-impregnated papers for deltamethrin, malathion and DDT respectively.

\section{Data analysis}

Mortality was corrected using Schneider-Orelli's formula [23] and interpreted following WHO recommendation to determine the susceptibility status. Larval bioassay data were analyzed using Log dose probit (Ldp) Line computer programme according to Finney method [24]. Chi-square $\left(x^{2}\right)$ test was used to estimate the goodness of fit, while liner regression $\left(r^{2}\right)$ was used to evaluate the data linearity. Lethal concentrations $\left(\mathrm{LC}_{10}, \mathrm{LC}_{50}\right.$ and $\mathrm{LC}_{99}$ ) along with the slope were estimated at 95\% confidence intervals $(\mathrm{CI})$. The resistance ratios (RRs) $\left(\mathrm{RR}_{50}\right.$ 


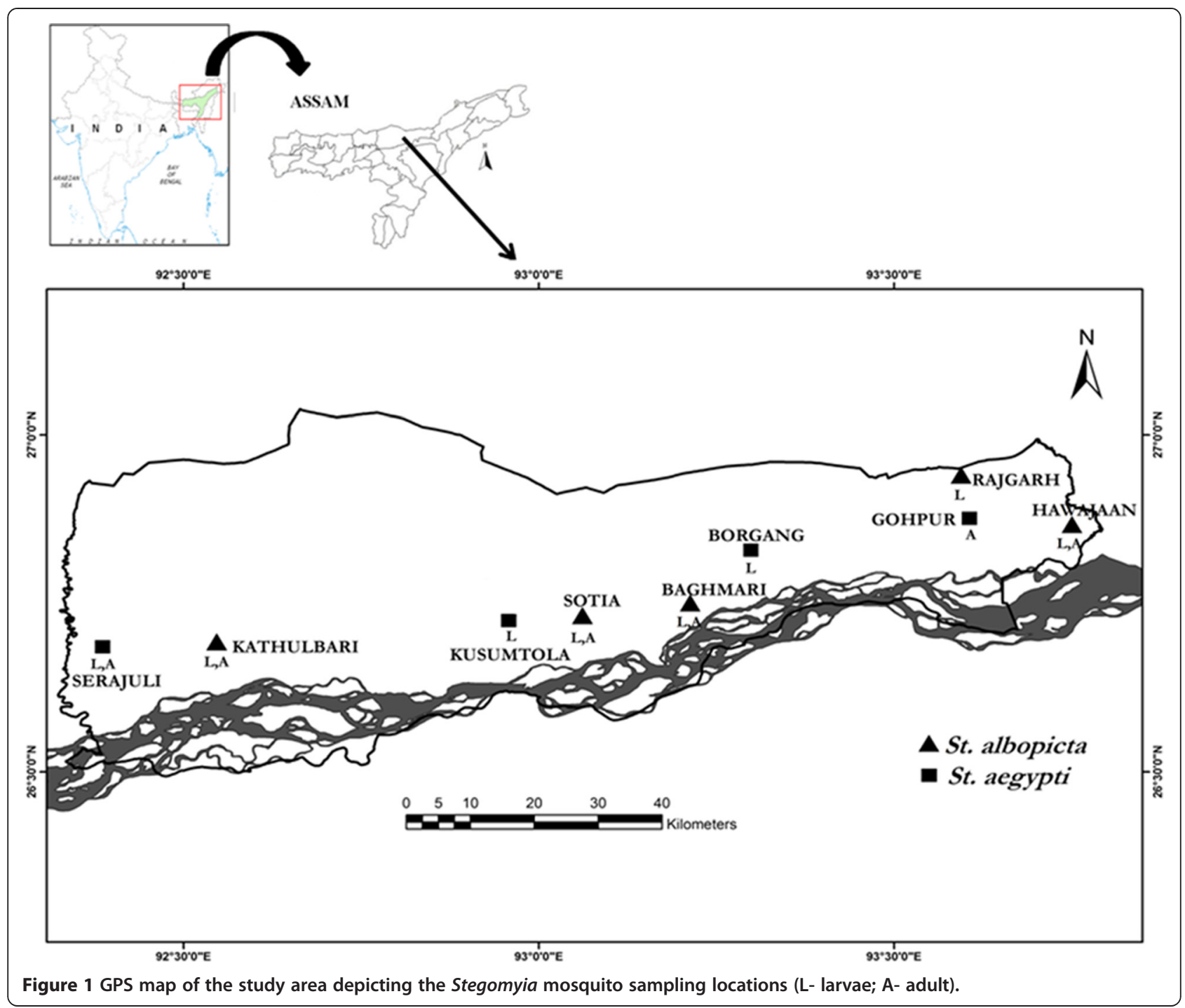

and $\mathrm{RR}_{99}$ ) were calculated by dividing the $\mathrm{LC}_{50}$ and $\mathrm{LC}_{99}$ values of WP with that of RP. A $R R_{99}$ of $<2$ corresponded to susceptible, whereas $>2$ was considered corresponding to the resistance. In adult bioassays, knockdown time $\left(\mathrm{KDT}_{10}, \mathrm{KDT}_{50}\right.$ and $\mathrm{KDT}$ 99) were determined using Ldp software, where overall significance of the multiple-tests was determined following Bonferroni procedure. The knock-down resistance ratios (KRRs) $\left(K_{R} R_{50}\right.$ and $\left.K R R_{99}\right)$ were calculated by dividing the $\mathrm{KDT}_{50}$ and $\mathrm{KDT}_{99}$ values of WP with that of RP. A $\mathrm{KRR}_{99}$ of $<2$ implied susceptible, while $>2$ was considered implying knock-down resistance in the WP St. albopicta and St. aegypti mosquitoes [16].

\section{Results}

St. albopicta and St. aegypti susceptibility to temephos Temephos susceptibility to St. albopicta was determined at Hawajan, Baghmari, Sotia and Kathulbari areas which suggested that all the populations were completely susceptible except in Sotia where the $\mathrm{LC}_{99}$ value was $0.12 \mathrm{mg} / \mathrm{l}$ and $\mathrm{RR}_{99}$ was 2.3 (Table 1 ). The $R R_{50}$ and $R R_{99}$ values among the study populations ranged from 1.4- 1.5 and 0.9- 2.3 respectively. The LC values obtained for St. albopicta populations did not follow normal distribution for mortality to the log dose $\left(x^{2} \geq 6.7 ; \mathrm{p} \leq 0.01\right)$. For St. aegypti, the populations of Rajgarh, Borgong, Kusumtola and Serajuli were tested for temephos sensitivity (Table 2). In Borgong, Kusumtola and Serajuli WP, the $\mathrm{RR}_{99}$ were $2.5,5.4$ and 4.5 respectively. The St. aegypti WP collected in Rajgarh was found to have incipient resistance as the $R_{50}$ and $R_{99}$ values were 1.9 each. The LC values obtained for St. aegypti larval bioassays in all the study populations did not exhibit linear probit between the log dose and mortality $\left(x^{2} \geq 7.8 ; \mathrm{p} \leq 0.02\right)$. 
Table 1 Temephos sensitivity of St. albopicta larvae and resistance ratio (RR) in the study populations

\begin{tabular}{|c|c|c|c|c|c|}
\hline Values & Hawajan $(\mathrm{N}=675)$ & Baghmari $(\mathrm{N}=675)$ & Sotia $(N=675)$ & Kathulbari $(\mathrm{N}=675)$ & $\mathrm{RS}(\mathrm{N}=350)$ \\
\hline $\mathrm{LC}_{10}$ & 0.0004 & 0.0004 & 0.0004 & 0.0006 & 0.0004 \\
\hline $\mathrm{LC}_{50}$ & 0.0028 & 0.0029 & 0.0029 & 0.0027 & 0.002 \\
\hline $\mathrm{LC}_{99}$ & 0.079 & 0.092 & 0.12 & 0.044 & 0.052 \\
\hline$x^{2}(p)$ & $10.8(0.004)$ & $11.7(0.003)$ & $6.7(0.01)$ & $13.7(0.001)$ & $1.3(0.6)$ \\
\hline Slope & $1.60 \pm 0.1$ & $1.55 \pm 0.1$ & $1.44 \pm 0.2$ & $1.89 \pm 0.2$ & $1.64 \pm 0.2$ \\
\hline r & 0.98 & 0.97 & 0.96 & 0.97 & 0.99 \\
\hline g & 0.68 & 0.74 & 13.6 & 0.89 & 0.30 \\
\hline $\mathrm{RR}_{50}(95 \% \mathrm{Cl}) / \mathrm{RR}_{99}(95 \% \mathrm{Cl})$ & $1.4(1.2-1.7) / 1.5(1.3-1.8)$ & $1.5(1.2-1.7) / 1.8(1.5-2.1)$ & $1.5(1.2-1.7) / 2.3(2.0-2.6)$ & $1.4(1.1-1.6) / 0.9(0.7-1.1)$ & - \\
\hline
\end{tabular}

$\mathrm{N}$ - number; LC10/50/99- lethal concentration 10\%/50\%/99\%.

Insecticides toxicity to field populations of adult St. albopicta and St. aegypti

Adult insecticide susceptibility bioassay for St. albopicta were performed in WP of Hawajan, Sotia and Kathulbari, while for St aegypti, the bioassays were carried out for WP of Gohpur, Kusumtola and Serajuli. The results of adult susceptibility bio-assay for St. albopicta and St. aegypti have been shown in Tables 3 and 4 respectively. After 24 hours post exposure, the percent corrected mortality obtained for DDT ranged from 45.2 to 59.4 among the St. albopicta populations, while 65.0 to 70.5 among the St. aegypti populations. However the corrected mortality obtained in RP of St. albopicta was 80.0-85.0\%, where in St aegypti varied from 84.5 to 88.0 percent against DDT. Results suggested that both St. albopicta and St. aegypti WP were fully resistant to DDT in all the study locations. Both the species were completely susceptible to deltamethrin and malathion (corrected mortality $>98 \%$ ), except for St. albopicta at Sotia which showed low level of resistance to malation (corrected mortality $=95.4 \%$ ). The mortality obtained in St. albopicta RP was $100 \%$ for deltamethrin and $95-100 \%$ for malathion. Similarly for St. aegypti RP, the percent corrected mortality against both deltamethrin and malathion was $100 \%$. The KDT values determined for DDT and deltamethrin for all the study WP and malathion for
St. aegypti Kusumtola WP displayed a linear probit for knock-down rates with time (Tables 3 and 4). The estimated KDT of DDT for St. albopicta indicated that KDT values (both $\mathrm{KDT}_{50}$ and $\mathrm{KDT}_{99}$ ) for WP were $>2$ folds $(2.1-4.7)$ higher to those of RP except for $\mathrm{KDT}_{50}$ in Hawajan WP (1.1 folds). In case of St. aegypti also there was $>2$ fold rise in the $\mathrm{KDT}_{50}(2.1-2.4)$ and $\mathrm{KDT}_{99}(2.1-3.3)$ among the test populations. The results suggest that high level of DDT knock-down resistance was present among both the Stegomyia species. For deltamethrin, the $\mathrm{KRR}_{50}$ and $\mathrm{KRR}_{99}$ values were below 2 in all the test populations of both the species which indicates the knock-down sensitivity among the test WP. For malathion, both $\mathrm{KRR}_{50}$ and $\mathrm{KRR}_{99}$ for St. albopicta ranged from 1.7 to 1.9 (for $\mathrm{KRR}_{50}$ ) and 1.9 to 2.1 (for $\mathrm{KRR}_{99}$ ) in the test populations. However for St. aegypti WP, the $\operatorname{KRR}_{50}(2.1-2.9)$ and $\mathrm{KRR}_{99}(2.6-3.7)$ values were $>2$ folds higher in all the test populations as compared to the RP. St. aegypti was confirmed knock-down resistant to malathion whereas St. albopicta may have developed low level of knock-down resistance in Sotia WP.

\section{Discussion}

Northeastern region of India is geographically isolated from the mainland of India and has been an important

Table 2 Temephos sensitivity of St. aegypti larvae and resistance ratio (RR) in the study populations

\begin{tabular}{|c|c|c|c|c|c|}
\hline Values & Rajgarh $(\mathrm{N}=675)$ & Borgong $(\mathrm{N}=675)$ & Kusumtola $(\mathrm{N}=675)$ & Serajuli $(N=675)$ & $\mathrm{RS}(\mathrm{N}=250)$ \\
\hline$\overline{L C_{10}}$ & 0.0005 & 0.0005 & 0.0004 & 0.0005 & 0.0003 \\
\hline $\mathrm{LC}_{50}$ & 0.0031 & 0.0035 & 0.0037 & 0.0041 & 0.0016 \\
\hline $\mathrm{LC}_{99}$ & 0.086 & 0.11 & 0.24 & 0.2 & 0.044 \\
\hline$x^{2}(p)$ & $11.1(0.004)$ & $12.6(0.002)$ & $8.7(0.01)$ & $7.8(0.02)$ & $0.4(0.5)$ \\
\hline Slope & $1.60 \pm 0.1$ & $1.54 \pm 0.1$ & $1.28 \pm 0.1$ & $1.38 \pm 0.1$ & $1.60 \pm 0.3$ \\
\hline r & 0.98 & 0.97 & 0.98 & 0.98 & 0.99 \\
\hline g & 0.67 & 0.77 & 0.73 & 0.60 & 0.10 \\
\hline $\mathrm{RR}_{50}(95 \% \mathrm{Cl}) / \mathrm{RR}_{99}(95 \% \mathrm{Cl})$ & $1.9(1.6-2.2) / 1.9(1.6-2.1)$ & $2.2(1.9-2.4) / 2.5(2.2-2.8)$ & $2.3(2.0-2.6) / 5.4(4.9-5.9)$ & $2.6(2.3-2.9) / 4.5(4.1-5.0)$ & - \\
\hline
\end{tabular}

$\mathrm{N}$ - number; LC10/50/99- lethal concentration 10\%/50\%/99\%. 
Table 3 Mortality and knock-down in St. albopicta (WP) against different insecticides

\begin{tabular}{|c|c|c|c|c|c|c|c|c|c|}
\hline & Insecticide (N) & CM (\%) & $\mathrm{KDT}_{10}(95 \% \mathrm{Cl})$ & $\mathrm{KDT}_{50}(95 \% \mathrm{Cl})$ & $\mathrm{KDT}_{99}(95 \% \mathrm{Cl})$ & $x^{2}(p)$ & Slope & $\begin{array}{l}\mathrm{KRR}_{50} / \\
\mathrm{KRR}_{99} \\
\end{array}$ & $\begin{array}{l}95 \% \mathrm{Cl} \text { for } \\
\mathrm{KRR}_{50} / \mathrm{KRR}_{\mathbf{9 9}} \\
\end{array}$ \\
\hline \multirow[t]{3}{*}{ Hawajan } & DDT (106) & 59.4 & $25.6(22.3-28.4)$ & $71.1(62.8-84.7)$ & $452.0(296.3-853.5)$ & $6.0(0.7)$ & $2.9 \pm 0.2$ & $1.1 / 2.6$ & $0.9-1.3 / 2.3-2.9$ \\
\hline & DM (113) & 100.0 & $3.2(2.4-3.9)$ & $9.6(8.5-10.7)$ & $72.5(58.3-96.4)$ & $6.8(0.2)$ & $2.7 \pm 0.2$ & $1.7 / 1.6$ & 1.4-1.9/1.4-1.9 \\
\hline & MA (107) & 99.1 & $25.0(18.4-28.4)$ & $83.0(73.9-127.7)$ & $731.7(601.3-3009.4)$ & $35.1(<0.0001)$ & $2.5 \pm 0.2$ & $1.7 / 1.9$ & $1.5-1.9 / 1.6-2.2$ \\
\hline \multirow[t]{3}{*}{ Sotia } & DDT (163) & 50.8 & $26.7(21.9-30.5)$ & $92.1(74.2-132.9)$ & $872.8(435.9-3001.7)$ & $6.8(0.7)$ & $2.4 \pm 0.3$ & $2.1 / 4.7$ & $1.8-2.4 / 4.3-5.1$ \\
\hline & DM (182) & 98.8 & $4.0(3.1-4.8)$ & $9.3(8.3-10.2)$ & $43.1(36.1-54.2)$ & $5.4(0.3)$ & $3.5 \pm 0.3$ & $1.1 / 1.2$ & $0.9-1.3 / 1.0-1.5$ \\
\hline & MA (105) & 95.4 & $27.6(15.2-30.9)$ & $77.6(74.6-186.7)$ & $508.8(495.9-1203.2)$ & $50.3(<0.0001)$ & $2.8 \pm 0.4$ & $1.8 / 2.1$ & $1.6-2.1 / 1.8-2.4$ \\
\hline \multirow[t]{3}{*}{ Kathulbari } & DDT (126) & 45.2 & $26.2(23.2-28.8)$ & 84.8 (73.5-103.7) & $712.8(45.6-1418.4)$ & $14.2(0.1)$ & $2.5 \pm 0.2$ & $2.1 / 3.3$ & $1.8-2.4 / 2.9-3.7$ \\
\hline & DM (112) & 100.0 & $3.3(2.5-4.1)$ & $8.0(7.0-8.9)$ & $39.3(32.9-49.5)$ & $7.0(0.2)$ & $3.4 \pm 0.3$ & $0.9 / 1.0$ & $0.7-1.1 / 0.8-1.2$ \\
\hline & MA (113) & 99.1 & $21.2(15.4-24.2)$ & 71.7 (63.1-101.8) & $654.1(532.2-2116.5)$ & $36.7(<0.0001)$ & $2.4 \pm 0.2$ & $1.9 / 1.9$ & $1.6-2.2 / 1.7-2.2$ \\
\hline
\end{tabular}

WP- wild population; $\mathrm{N}$ - number; $\mathrm{CM}$ - corrected mortality; $\mathrm{Cl}$ - confidence interval; DM- deltamethrin; MA- malathion.

centre of mosquito-borne diseases in India. Mosquito vector control using insecticides is the primary element which argues that determination of insecticide resistance status of mosquitoes is inevitable. Current study has investigated the insecticide resistance status of St. albopicta and St. aegypti and determined the knock-down resistance in some sentinel locations in Assam state of northeastern India.

Present study found that the majority of the field populations of St. albopicta were susceptible to temephos $\left(R R_{99}<2\right)$, however in Sotia, the $R R_{99}$ of 2.3 suggested that an incipient level of temephos resistance was present in the test population as compared to the RP. The $\mathrm{LC}_{50}$ and $\mathrm{LC}_{99}$ values were quite high for St. aegypti field populations. The $\mathrm{LC}_{50}$ ranged from 0.0031 in Rajgarh WP to 0.0041 in Serajuli WP, while the $\mathrm{LC}_{99}$ ranged from 0.086 in Rajgarh to 0.24 in Kusumtola WP respectively. Both $R_{50}$ and $R_{99}$ values were found to be above 2 in the St. aegypti field populations of Borgang, Kusumtola and Serajuli which strongly evidences the development of resistance in these populations. The RR values in St. aegypti WP in Rajgarh were 1.9 each and suggested that a high level of physiological resistance may develop shortly due to continuous selection pressure.

In the present study although the $\mathrm{LC}_{99}$ value obtained for both the mosquito species were below the recommended dose of application of temephos as larvicide $[4,25]$, but are above the $\mathrm{LC}_{99}$ values obtained for the $\mathrm{RP}$. The principal intervention to control dengue vector in India involves the application of temephos formulation not exceeding the concentration of $1 \mathrm{mg} / \mathrm{l}$ to the domestic and peridomestic water containers, but it is not considered appropriate to set a formal guideline value for the insecticides as vector control agents in water [5]. Therefore determining dose for the control of vector mosquitoes and their level of sensitivity to larvicide at local level is important.

Resistance to temephos has been reported in many Southeast Asian countries [7-9]. However, the present results have suggested that St. albopicta is susceptible to temephos but the mortality data did not follow linear trend with the dose. A recent study has suggested that St. albopicta larvae were susceptible to temephos in northeast India and the data obtained followed linear

Table 4 Mortality and knock-down in St. aegypti (WP) against different insecticides

\begin{tabular}{|c|c|c|c|c|c|c|c|c|c|}
\hline & Insecticide (N) & CM (\%) & $\mathrm{KDT}_{10}(95 \% \mathrm{Cl})$ & $\mathrm{KDT}_{50}(95 \% \mathrm{Cl})$ & $\mathrm{KDT}_{99}(95 \% \mathrm{Cl})$ & $x^{2}(p)$ & Slope & $\begin{array}{l}\mathrm{KRR}_{50} / \\
\mathrm{KRR}_{99}\end{array}$ & $\begin{array}{l}95 \% \mathrm{Cl} \text { for } \\
\mathrm{KRR}_{50} / \mathrm{KRR}_{99}\end{array}$ \\
\hline \multirow[t]{3}{*}{ Gohpur } & DDT (116) & 70.5 & $23.0(19.1-26.1)$ & $65.5(57.5-79.6)$ & 441.1 (276.5-929.0) & $3.2(1.0)$ & $2.8 \pm 0.3$ & $2.4 / 2.3$ & $2.1-2.7 / 1.9-2.7$ \\
\hline & DM (177) & 100.0 & $3.2(2.4-4.0)$ & $7.0(6.1-7.8)$ & $28.8(23.2-39.6)$ & $2.1(0.3)$ & $3.8 \pm 0.4$ & $1.3 / 1.2$ & $1.1-1.5 / 1.0-1.4$ \\
\hline & MA (100) & 100.0 & $19.0(12.5-22.3)$ & $64.5(55.1-95.0)$ & $592.1(27.8-2510.7)$ & $25.4(0.005)$ & $2.4 \pm 0.3$ & $2.9 / 2.9$ & $2.6-3.2 / 2.6-3.3$ \\
\hline \multirow[t]{3}{*}{ Kusumtola } & DDT (142) & 69.0 & $23.7(17.9-28.0)$ & $83.2(66.2-126.1)$ & $813.0(78.4-3640.0)$ & $5.7(0.8)$ & $2.3 \pm 0.4$ & $2.1 / 2.1$ & $1.8-2.4 / 1.8-2.4$ \\
\hline & DM (150) & 98.0 & $3.4(1.6-4.7)$ & $10.1(8.2-12.1)$ & $53.5(39.5-107.5)$ & $3.1(0.08)$ & $2.7 \pm 0.6$ & $1.6 / 1.7$ & $1.4-1.9 / 1.5-1.9$ \\
\hline & MA (150) & 100.0 & $21.9(17.1-25.6)$ & $76.8(63.5-104.4)$ & $751.2(90.9-2338.4)$ & $8.1(0.6)$ & $2.3 \pm 0.3$ & $2.5 / 2.6$ & $2.2-2.9 / 2.3-2.9$ \\
\hline \multirow[t]{3}{*}{ Serajuli } & DDT (92) & 65.0 & $.1-26.6)$ & $99.5(76.6-158.9)$ & $1483.5(618.5-7662.7)$ & $6.8(0.7)$ & $2.0 \pm 0.3$ & $2.2 / 3.3$ & $1.9-2.5 / 2.9-3.7$ \\
\hline & DM (116) & 100.0 & $3.8(1.1-5.4)$ & $11.7(10.1-14.3)$ & $39.6(34.9-46.6)$ & $9.1(0.2)$ & $3.2 \pm 0.3$ & $1.3 / 1.4$ & $1.1-1.5 / 1.2-1.7$ \\
\hline & MA (100) & 98.3 & $14.1(6.5-16.1)$ & $65.6(55.8-125.5)$ & $1063.8(1033.6-13912.4)$ & $37.9(0.0)$ & $1.9 \pm 0.2$ & $2.1 / 3.7$ & $1.8-2.4 / 3.3-4.1$ \\
\hline
\end{tabular}

WP- wild population; N- number; CM- corrected mortality; Cl- confidence interval; DM- deltamethrin; MA- malathion. 
trend of mortality with dose [16]. Similarly, another study in the urban setting of Assam, India suggested that both St. aegypti and St. albopicta were completely sensitive to temephos and the $\mathrm{LC}_{95}$ concentrations were about 66 folds lower for St. aegypti and about 345 folds lower for St. albopicta as compared to the standard diagnostic concentration [4].

A high level of physiological resistance to insecticides could develop under the influence of selection pressure. A previous study has shown that the offspring of the survivors of selection pressure exhibited significantly reduced mortality and displayed about 298 folds increase in the $\mathrm{LC}_{50}$ values as compared to the F0 colony [26]. The RR values for the most efficient dengue vector $S t$. aegypti in majority of populations rose above 2 probably due to the selection of insecticide. The results suggest that St. aegypti WP were more resistant than the St. albopicta WP as the LC values and RR were higher for St. aegypti populations. St. aegypti might be under the influence of insecticide selection because is prefers to rest indoors and probably experiences more exposure to the household insecticides as compared to St. albopicta which opts to resting outdoors [7].

DDT use is widespread for controlling malaria vector mosquitoes and other vector-borne diseases in the region, whereas synthetic pyrethroid are used in long lasting insecticidal bed nets (LLIN) [14,15]. Adult susceptibility bioassay results suggest that field populations of known dengue vectors St. albopicta and St. aegypti displayed a high level of phenotypic resistance to DDT. The corrected mortality obtained for DDT in different populations of St. albopicta ranged from 45.2 to 59.4, while for St. aegypti ranged from 65 to 70.5. Interestingly the corrected mortality was higher in St. aegypti populations as compared to St. albopicta suggesting that St. aegypti were comparatively more sensitive to DDT. The RP of both the species used in the present study have shown mortality ranging between 80.0-88.0 percent for DDT, which indicated that a considerable level of DDT resistance has developed even in the laboratory reared population. The $\mathrm{KDT}_{99}$ value for St. albopicta ranged from 452.0 minutes in Hawajan to 872.8 minutes in Sotia, while for St. aegypti the $\mathrm{KDT}_{99}$ values ranged from 441.1 in Gohpur to 1483.5 in Serajuli. The KDT values obtained for DDT in the current study have suggested that both the tested species populations have developed potential knock-down resistance to DDT as compared to the RP. DDT resistance among the different species of vector mosquitoes has been well reported during recent years $[4,14-16,26]$. Previous studies have suggested that continuous and indiscreet use of DDT in vector-borne disease control intervention has led to the development and spatial spread of resistance among many efficient vector mosquitoes $[4,11,14-16,26]$. Our results are in line with the previous study which demonstrated that potential dengue vector St. albopicta was knock-down resistant to DDT, while sensitivity to malathion and deltamethrin was potentially reduced [16]. Resistance to DDT in Stegomyia mosquitoes has been associated with the mutation in $\mathrm{kdr}$ gene of voltage-gated sodium channel, however increased enzyme activity of detoxifying enzymes such as glutathione S-transferases and mixed function oxidases can also play a key role in DDT resistance [27-29]. Although many studies have recorded DDT resistance in Stegomyia mosquito in India and neighbouring countries the underlying mechanisms largely remain unclear $[4,11,16,21]$.

All the mosquito populations were completely susceptible to deltamethrin and the corrected mortality ranged from 98 to 100 percent. Both $K_{R} R_{50}$ and $K R R_{99}$ values were below 2 for both the species in all the populations which indicated the knock-down susceptibility of mosquitoes. The probit model suggested that the deltamethrin KDT values obtained for each population displayed a linear relationship. A varied level of response to deltamethrin and permethrin was observed in a recent study, where St. aegypti were resistant to deltamethrin as well as permethrin, but St. albopicta were susceptible to deltamethrin [4]. Recently, synthetic pyrethroid have been used tremendously in mosquito control which has reduced the sensitivity of mosquito to pyrethroids in many regions $[4,8,9,28,29]$ under the influence of multiple mechanisms [30], however the current results suggest that synthetic pyrethroids are equally effective against the dengue vectors. The results further emphasize that the resistance to DDT has not conferred any cross resistance to deltamethrin. Malathion is used widely in the control of mosquito vectors during epidemics in most parts of India, however the resistance to malathion in dengue vectors has not been reported in the northeastern region of India $[4,16]$. The test populations of both the species were sensitive to malathion as the corrected mortality was above 98 percent, however St. albopicta WP of Sotia exhibited 95.4 percent mortality which suggests the developed lower level of resistance to malathion. The KRR 99 value of Sotia WP was 2.1, which further confirms the incipient level of knock-down resistance. Interestingly the KRR values for St. aegypti were well above 2 among all the test populations which shows evidence that there has been development and spread of knock-down resistance against malathion in the region. Recent studies have reported that dengue vectors are fully susceptible however the $\mathrm{KDT}_{50}$ in St. albopicta was found to be 3.2 folds higher than the reference $[4,16]$. Considering the fact that malathion is routinely used in the anti-mosquito fogging operations during the peak epidemic periods of Japanese encephalitis and dengue in northeastern states, the dengue vectors are at 
continuous selection which might reduce sensitivity to malathion.

The purpose of this study was to evaluate the insecticide resistance status of larval and adult stages of St. albopicta and St. aegypti populations in different places of Assam to verify the expected success in dengue vector control programmes using insecticides. Insecticide resistance is vital, which can potentially compromise the mosquito vector control efforts and affect the efficiency of insecticides under field conditions. In India, DDT use is widespread in vector control intervention but its role against Stegomyia mosquitoes appears to be limited since it is largely used in indoor sprays $[14,15,25]$. However it is possible that excessive and routine use of DDT exerted indirect selection pressure on both the Stegomyia species. Previous studies have suggested that longterm use of DDT in different vector control programmes has led to DDT selection in Stegomyia and other mosquito species [12,30,31]. Therefore, monitoring and detecting resistance at early stage may improve vector control interventions by pre-emptively triggering the evidence based implementation of alternative control strategies for achieving promising results [32]. Since dengue vector is expanding its spread rapidly in northeastern states, the spatial data on the effectiveness of insecticides used in control measures is crucial.

\section{Conclusion}

Current research has generated sufficient data on the susceptibility status of two dengue vector species for selecting insecticide in the dengue control operations. Both St. albopicta and St. aegypti populations were completely resistant to DDT, but completely susceptible to deltamethrin. There has been a decrease in the susceptibility to malathion in adult stages and susceptibility to temephos in larval stages in some of the study populations. We recommend the regular monitoring of insecticide resistance in a large geographical area to pin-point the level of resistance in different areas to warrant the use of insecticides to which even a minimum level of resistance is observed.

\section{Competing interests}

The authors declare that they have no competing interests.

\section{Authors' contributions}

KY, SD and BR designed the experiments and performed the field study. KY and BR performed the laboratory studies. SD and KY analysed the data and performed stastical analysis. KY and SD prepared the manuscript. W and BR critically reviewed the manuscript. All the authors have read and approved the final manuscript.

\section{Acknowledgements}

Authors are thankful to Mr PK Sarkar, IDST Scientist, Defence Research and Development Organisation, India for his support and encouragement during the study.
Received: 6 November 2014 Accepted: 18 February 2015

Published online: 03 March 2015

\section{References}

1. World Health Organization (WHO). Global strategy for dengue prevention and control 2012-2020. Geneva, Switzerland: WHO press; 2012. p. 1-34.

2. Tewari SC, Thenmozhi V, Katholi CR, Manavalan R, Munirathinam A, Gajanana A. Dengue vector prevalence and virus infection in a rural area in south India. Trop Med Int Health. 2004;9(4):499-507.

3. Kumari R, Kumar K, Chauhan LS. First dengue virus detection in Aedes albopictus from Delhi, India: Its breeding ecology and role in dengue transmission. Trop Med Int Health. 2011;16(8):949-54.

4. Dev V, Khound K, Tewari GG. Dengue vectors in urban and suburban Assam, India: entomological observations. WHO South-East Asia J Pub Health. 2014:3(1):51-9.

5. World Health Organization (WHO). Dengue guidelines for diagnosis, treatment, prevention and control: new edition. Geneva: World Health Organization; 2009. WHO/HTM/NTD/DEN/2009.1.

6. Grisales N, Poupardin R, Gomez S, Fonseca-Gonzalez I, Ranson H, Lenhart A. Temephos resistance in Aedes aegypti in Colombia compromises dengue vector control. PLoS Negl Trop Dis. 2013;7(9):e2438.

7. Chen CD, Nazni WA, Lee HL, Sofian-Azirun M. Susceptibility of Aedes aegypti and Aedes albopictus to temephos in four study sites in Kuala Lumpur City Center and Selangor State, Malaysia. Trop Biomed. 2005:22:207-16.

8. Dusfour I, Thalmensy V, Gaborit P, Issaly J, Carinci R, Girod R. Multiple insecticide resistance in Aedes aegypti (Diptera: Culicidae) populations compromises the effectiveness of dengue vector control in French Guiana. Mem Inst Oswaldo Cruz. 2011;106(3):346-52.

9. Khan HAA, Akram W, Shehzad K, Shaalan EA. First report of field evolved resistance to agrochemicals in dengue mosquito, Aedes albopictus (Diptera: Culicidae), from Pakistan. Parasit Vect. 2011;4:146.

10. Selvi S, Edah MA, Nazni WA, Lee HL, Tyagi BK, Sofian-Azirun M, et al. Insecticide susceptibility and resistance development in malathion selected Aedes albopictus (Skuse). Trop Biomed. 2010;27(3):534-50.

11. Singh RK, Dhiman RC, Mittal PK, Dua VK. Susceptibility status of dengue vectors against various insecticides in Koderma (Jharkhand), India. J Vector Borne Dis. 2011:48:116-8.

12. Kamgang B, Marcombe S, Chandre F, Nchoutpouen E, Nwane P, Etang J, et al. Insecticide susceptibility of Aedes aegypti and Aedes albopictus in Central Africa. Parasit Vect. 2011;4:79.

13. Araujo AP, Diniz DFA, Helvecio E, de Barros RA, de Oliveira CMF, Ayres CFJ, et al. The susceptibility of Aedes aegypti populations displaying temephos resistance to Bacillus thuringiensis israelensis: a basis for management. Parasit Vect. 2013;6:297.

14. Dhiman S, Rabha B, Talukdar PK, Das NG, Yadav K, Baruah I, et al. DDT \& deltamethrin resistance status of known Japanese encephalitis vectors in Assam, India. Indian J Med Res. 2013;138:988-94.

15. Dhiman S, Rabha B, Goswami D, Das NG, Baruah I, Bhola RK, et al. Insecticide resistance and human blood meal preference of Anopheles annularis in Asom-Meghalaya border area, northeast India. J Vector Borne Dis. 2014;51:133-6.

16. Dhiman S, Rabha B, Yadav K, Baruah I, Veer V. Insecticide susceptibility and dengue vector status of wild Stegomyia albopicta in a strategically important area of Assam, India. Parasit Vect. 2014;7:295.

17. Nath MJ, Bora AK, Yadav K, Talukdar PK, Dhiman S, Baruah I, et al. Prioritizing areas for malaria control using geographical information system in an endemic district of Assam, India. Public Health. 2013;127:572-80.

18. World Health Organization (WHO). Guidelines for laboratory and field testing of mosquito larvicides. WHO/CDS/WHOPES/GCDPP.13, Geneva, Switzerland: World Health Organization; 2005.

19. World Health Organization (WHO). Test Procedures for insecticide resistance monitoring in malaria vectors, bio-efficacy and persistence of insecticide on treated surfaces, 1998. WHO/CDS/CPC/MAL/98.12, Geneva, Switzerland: World Health Organization; 1998.

20. Surendran SN, Kajatheepan A, Sanjeefkumar KF, Jude PJ. Seasonality and insecticide susceptibility of dengue vectors: an ovitrap based survey in a residential area of northern Sri Lanka. Southeast Asian J Trop Med Public Health. 2007;38:276-82

21. Komalamisra N, Srisawat R, Phanbhuwong T, Oatwaree S. Insecticide susceptibility of the dengue vector, Aedes aegypti L In metropolitan Bangkok. Southeast Asian J Trop Med Public Health. 2011;42(4):814-23. 
22. World Health Organization (WHO). Test Procedures for insecticide resistance monitoring in malaria vectors mosquitoes. Geneva, Switzerland: WHO press; 2013. p. 1-39.

23. Puntener W. Manual for field trials in plant protection second edition, 1981. Agricultural Division, Ciba-Geigy Limited.

24. Ldp: Log dose probit (Ldp) line software. Ehabsoft, Cairo Egypt [Available at: http://www.ehabsoft.com//dpline]

25. National Vector Borne Disease Control Programme (NVBDCP). Guidelines for integrated vector management for control of dengue/dengue haemorrhagic fever, 2014. Available at http://www.nvbdcp.gov.in/iec.html.

26. Sarkar M, Bhattacharyya IK, Borkotoki A, Baruah I, Srivastava RB. Development of physiological resistance and its stage specificity in Culex quinquefasciatus after selection with deltamethrin in Assam, India. Mem Inst Oswaldo Cruz. 2009;104(5):673-7.

27. Brengues C, Hawkes NJ, Chandre F, McCarroll L, Duchon S, Guillet P, et al. Pyrethroids and DDT cross-resistance in Aedes aegypti is correlated with novel mutations in the voltage-gated sodium channel gene. Med Vet Entomol. 2003;17:87-94.

28. Chareonviriyaphap T, Bangs MJ, Suwonkerd W, Kongmee M, Corbel V, Ngoen-Kla R. Review of insecticide resistance and behavioral avoidance of vectors of human diseases in Thailand. Parasit Vect. 2013;6:280.

29. Marcombe S, Farajollahi A, Healy SP, Clark GG, Fonseca DM. Insecticide resistance status of United States populations of Aedes albopictus and mechanisms involved. PLoS One. 2014:9(7):e101992.

30. Koou S, Chong C, Vythilingam I, Lee C, Ng L. Insecticide resistance and its underlying mechanisms in field populations of Aedes aegypti adults (Diptera: (ulicidae) in Singapore. Parasit Vect. 2014;7:471.

31. Yadouleton A, Badirou K, Agbanrin R, Jost H, Attolo R, Srinivasan R, et al. Insecticide resistance status in Culex quinquefasciatus in Benin. Parasit Vect. 2015;8:17.

32. Chattopadhyay P, Dhiman S, Devi KA, Banerjee S, Rabha B, Chaurasia A, et al. Ultra low concentration deltamethrin loaded patch development and evaluation of its repellency against dengue vector Aedes (S) albopictus. Parasit Vect. 2013;6:284.

\section{Submit your next manuscript to BioMed Central and take full advantage of:}

- Convenient online submission

- Thorough peer review

- No space constraints or color figure charges

- Immediate publication on acceptance

- Inclusion in PubMed, CAS, Scopus and Google Scholar

- Research which is freely available for redistribution 